\title{
Immunohistological Detection of B Lymphocytes in the Rat Lymphoid Organs by Using Anti-Rat B Lymphocyte Serum
}

\author{
Noboru Yamanaka,* Yoshifumi Ishit, Hirofumi Koshiba \\ and KокICHI KIKUCHI \\ Department of Pathology, Sapporo Medical College, Sapporo \\ 060
}

\begin{abstract}
YamanaKa, N., Ishit, Y., Koshiba, H. and KIKUCHI, K. Immunohistological Detection of $B$ Lymphocytes in the Rat Lymphoid Organs by Using Anti-Rat B Lymphocytes Serum. Tohoku J. exp. Med., 1981, 135 (2), 187-196 Anti-rat B lymphocyte serum (ARBS) was prepared by immunizing rabbits with purified $B$ cells from rat spleen and by absorbing the rabbit serum with rat red blood cells and syngeneic sarcoma cells. The specificity of ARBS for rat B cells was confirmed by various cytologic and immunofluorescence studies. By indirect immunofluorescence on tissue sections of rat spleen and lymph nodes, anatomical localizations of B cells in lymphoid organs were lymphoid follicles of the lymph node and lymphocyte corona surrounding periarteriolar lymphoid sheaths of the spleen; while cells located in the thymus-dependent area were essentially devoid of immunofluorescence or no cytoplasmic immunofluorescence was observed in plasma cells. Thus, the B cell distribution in tissue sections was clearly demonstrated with ARBS. When the cross-reactivity of ARBS with mouse B cells was studied by complement-dependent cytotoxicity and immunofluorescence, it was found that mouse $B$ cells shared at least one determinant of rat B lymphocyte specific antigens (RBLA) with rat $B$ cells, and that the distribution pattern of the cross-reacting antigens in mouse lymphoid tissues was essentially the same as that of RBLA in rat lymphoid organs. - rat lymphoid organs; anti-rat B lymphocyte serum; rat B lymphocyte specific antigens
\end{abstract}

It has become popular that mammalian lymphocytes are divided into two subpopulations, i.e., thymus-derived (T) lymphocytes and bone marrow-derived (B) lymphocytes.

Various surface markers of the lymphocytes were extensively examined and the relationships between surface markers and biological functions of lymphocytes became clear, especially in mice. Rats are also commonly used as experimental animals in this field of study. However, information about surface markers of rat lymphocytes is rather poor as compared with mouse lymphocytes.

In a previous paper (Ishii et al. 1976), we already reported on the production of heterologous antiserum specifically cytotoxic against rat $\mathrm{T}$ cells. This serum detected rat $\mathrm{T}$ lymphocyte specific antigens (RTLA), which were present in a

Received for publication, January 26, 1981.

* Present address: Department of Otolaryngology, Sapporo Medical College, Sapporo 060. 
higher concentration in peripheral $\mathrm{T}$ cells than in thymus cortical cells, and had apparent cross-reactability with mouse $\mathrm{T}$ cells.

In this paper, we report on the presence of rat B lymphocyte specific antigens (RBLA) detected by heterologous anti-rat B lymphocyte serum and the detection of B lymphocytes in the rat lymphoid organs by the immunofluorescence with this antiserum.

\section{Materials and Methods}

Animals. Inbred Wistar-King-Apteckman (WKA) rats were used. $\mathrm{CH} / \mathrm{He}$ and $\mathrm{A} / \mathrm{Jax}$ mice were obtained from our own bleeding colony.

Antisera. T lymphocytes were removed from rat spleen cell suspension by treating them with anti-rat T lymphocyte serum (ARTS) and complement (C). Killed T lymphocytes were removed by centrifugation on a Ficoll-Conray gradient $(d=1.078)$ and the cells at interface were collected and washed twice in phosphate-buffered saline (PBS). More than $85 \%$ of these cells were able to bind erythrocyte-antibody-complement (EAC) complexes and showed positive immunofluorescence by a direct immunofluorescent method with FITCconjugated rabbit anti-rat immunoglobulin serum. A contamination of spleen macrophages in the B cell suspension was below $3 \%$ as examined by phagocytic activity and cytochemical studies. Purified B cells $\left(5 \times 10^{7}\right)$ were suspended in PBS and injected intravenously into rabbits. The animals were boosted twice at 1 week intervals and bled 1 week later. The sera were heat inactivated $\left(56^{\circ} \mathrm{C}, 30 \mathrm{~min}\right)$ and stored at $-80^{\circ} \mathrm{C}$.

Cell suspensions. Cells obtained from thymuses, spleens, lymph nodes, and bone marrow were washed twice and suspended in RPMI-1640 medium. Cell clumps were removed by squeezing them between two pieces of slide glass, filtering through four sheets of cotton gauze, and sedimenting for 5 min. Dead cells and red blood cells (RBC) were removed following centrifugation on a Ficoll-Conray gradient at $250 \times \mathrm{g}$ for $20 \mathrm{~min}$. Peripheral blood lymphocytes (PBL) separated on a Ficoll-Conray gradient were also suspended in RPMI-1640 medium.

Absorption procedure. Rabbit antiserum raised against rat spleen B cells (ARSS) was absorbed twice with 1:1 packed volume of rat RBC and glutaraldehyde insolubilized rat serum. Aliquots of the serum were diluted to $1: 10$ and further absorbed syngeneic sarcoma cells (KMT-17). As judged by immunoelectrophoresis assay, this reagent had no detectable anti-immunoglobulin activity, and was referred to as anti-rat B lymphocyte serum (ARBS).

For quantitative absorption studies, $1 \mathrm{ml}$ of 1:20 diluted ARSS was incubated with graded numbers of cells from different sources at $4^{\circ} \mathrm{C}$ for $30 \mathrm{~min}$. The serum was also absorbed with packed liver and brain homogenates. The absorbents were removed by centrifugation at $7000 \times \mathrm{g}$ for $10 \mathrm{~min}$.

Cytotoxicity test. Complement-dependent cytotoxicity was determined by the trypan blue dye exclusion test using normal rabbit serum as a source of complement (C). The rabbit serum was absorbed with rat $\mathrm{RBC}$ to remove natural antibodies. Equal volume of target cell suspension $\left(5 \times 10^{6} / \mathrm{ml}\right)$, antiserum, and $\mathrm{C}$ were mixed and incubated at $37^{\circ} \mathrm{C}$ for $30 \mathrm{~min}$. Lysed cells were judged by uptake of trypan blue, estimating the cytotoxic index (CI) as

$$
\frac{\% \text { alive in } \mathrm{C} \text { control }-\% \text { alive in experimental }}{\% \text { alive in } \mathrm{C} \text { control }} \times 100 \%
$$

Immunofluorescence. Cryostat sections of rat and mouse lymphoid tissues were placed on glass slides and fixed in acetone for $10 \mathrm{~min}$ in a wet box at room temperature. After washing three times with PBS, goat anti-rabbit IgG serum labeled with fluorescein isothiocyanate (Miles Laboratories, Elkhart, Ind.) was placed on the tissue section for $40 \mathrm{~min}$ in a wet box at room temperature. The slides were washed three times with PBS and mounted 
with cover slips in buffered glycerin. The sections were examined in a Nikon Fluophoto microscope with a high pressure mercury lamp. Normal rabbit sera, obtained before immunization of each rabbit, were used as controls in each experiment.

Lymphocyte culture. Spleen cells of WKA rats were suspended at a concentration of $2 \times 10^{6}$ in $1 \mathrm{ml}$ of RPMI-1640 with $10 \%$ fetal calf serum, containing $2.5 \mu \mathrm{l}$ of phytohemagglutinin (PHA-P, Difco Laboratories, Detroit, Mich.) or $2.5 \mu \mathrm{g}$ of concanavalin A (Con A, Sigma Chemical Company, St. Louis, Mo.). The cells were cultured for $68 \mathrm{hr}$ and then labeled with $1 \mu \mathrm{l}$ of tritiated thymidine (Radiochemical Center, Amersham). Four hr later, the cells were washed twice in cold $5 \%$ trichloracetic acid and solubilized in Soluene-100 Packard, Zurich). Radioactivity was counted in a Beckmann LS-100 scintillation counter.

Rosette test. Lymphocytes rosetting with erythrocyte-antibody-complement (EAC) complex was detected by the method described previously (Ishii et al. 1975). The percentage of cells binding more than two erythrocytes was counted.

\section{Results}

\section{Cytotoxicity test}

The results are summarized in Table 1. Aliquots of ARBS were tested for cytotoxicity against cells from various lymphoid organs. In a parallel series of tubes, EAC rosette tests and membrane immunofluorescence using FITC-conjugated rabbit anti-rat immunoglobulin serum were performed.

The percentage of cells lysed by ARBS in the spleen, lymph node and PBL was correlated with EAC-binding cells and sIg-positive cells. ARBS at the working dilution was entirely nontoxic for thymus cells. The cross-reactivity of ARBS with mouse B cells was studied by C-dependent cytotoxicity and indirect immunofluorescence. ARBS was effective on spleen cells and lymph node cells from WKA rats and A/Jax mice. One absorption of ARBS with mouse spleen cells and lymph node cells could remove cytotoxicity against mouse target cells but failed to abolish that against rat target cells.

TABLE 1. Percentages of rat lymphoid cells from different sources lysed. by ARBS or associated with surface Ig and complement receptor

\begin{tabular}{lcrc}
\hline Lymphoid cells & ARBS & sIg* & C-receptor $\dagger$ \\
\hline Thymus & 11 & 0 & 0 \\
Lymph node & 40 & 42 & 37 \\
Spleen & 56 & 61 & 60 \\
Bone marrow & 5 & 6 & 9 \\
PBL $\ddagger$ & 30 & 28 & 28 \\
\hline
\end{tabular}

* Dected by FITC-conjugated rabbit anti-rat IgG.

$\uparrow$ Detected by sheep erythrocyte-antibody-complement (EAC) rosette assay.

$\ddagger$ Peripheral blood lymphocyte.

\section{Quantitative absorption}

To determine the tissue distribution of rat $\mathrm{B}$ cell antigen, 1/20 dilution of ARBS was absorbed with increasing numbers of various cells and was tested for cytotoxicity against spleen cells. The results are summarized in Table 2. 
TABLE 2. Absorptive capacities of tissue and cells from different sources for cytotoxicity of ARBS on spleen cells

\begin{tabular}{|c|c|c|c|c|c|}
\hline \multirow{2}{*}{ Cells } & \multirow{2}{*}{ used for absorption* } & \multicolumn{4}{|c|}{ Number of cells $\left(10^{9}\right)$} \\
\hline & & $1 / 2$ & $1 / 4$ & $1 / 8$ & $1 / 16$ \\
\hline & Thymus & $H+$ & m & H & H \\
\hline & Spleen & - & - & + & \# \\
\hline & Lymph node & - & + & $H$ & H \\
\hline & Bone marrow & nd & nd & nd & nd \\
\hline & Liver & H & $H$ & H & H \\
\hline & Brain & Ht & m & H & W \\
\hline
\end{tabular}

* $1 \mathrm{ml}$ of 1: 50 diluted anti-rat spleen cells serum was absorbed with graded numbers of cells or $1 / 2$ to $1 / 16 \mathrm{ml}$ of tissue homogenates.

$\dagger$ Cytotoxic index $(\%): 0$ to $25(-)$, to $50(+)$, to $75(+)$, to $100(\mathrm{HI})$; nd, not done.

The absorption with spleen cells and lymph node cells led to a stepwise fall in residual cytotoxicity to the target cells. When thymus cells were used for the absorption, anti-spleen cell cytotoxicity slightly got down. The absorptive capacity of thymus cells, however, was about $10 \%$ of that of spleen cells. When the cell number required to reduce anti-spleen cell cytotoxicity to $50 \%$ was compared between spleen cells and lymph node cells, the absorptive capacity of spleen cells was about 2 times as high as that of lymph node cells. One ml of the same dilution of ARBS was also absorbed with $1 / 16$ to $1 / 2 \mathrm{ml}$ of packed liver and brain homogenates, which failed to remove any cytotoxicity against spleen cells (Table 2).

\section{Functional studies}

In order to evaluate the $\mathrm{B}$ cell-specificity of ARBS functionally, WKA spleen cells were treated with ARBS and $\mathrm{C}$ and then were cultured with PHA and Con A (Table 3). The lymphocytes treated with medium and $\mathrm{C}$ responded well to

\begin{tabular}{|c|c|c|}
\hline \multirow{2}{*}{ Mitogen } & \multicolumn{2}{|c|}{ CPM* } \\
\hline & Medium $+\mathrm{C}$ & $\mathrm{ABS}+\mathrm{C}$ \\
\hline None & $2649 \pm 191.7$ & $2418 \pm 107.3$ \\
\hline PHA $(1.25 \mu \mathrm{l} / \mathrm{ml})$ & $6407 \pm 348.5$ & $5851 \pm 438.2$ \\
\hline Con A $(1.25 \mu \mathrm{l} / \mathrm{ml})$ & $11517 \pm 822.8$ & $4918 \pm 476.6$ \\
\hline
\end{tabular}

both mitogens. Similarly, the cells treated with ARBS and C showed good mitogenic response to PHA. The Con A response, however, was suppressed significantly in ARBS and $\mathrm{C}$ treated cells. 
Immunofuorescence

Direct and indirect immunofluorescent methods were carried out on tissue sections of normal rats thymus, spleen and lymph node using fluoresceinated rabbit anti-rat various heavy chains sera, ARBS, and fluoresceinated goat antirabbit IgG serum. ARBS did not stain thymocytes at the working dilution, but reacted selectively with lymphocytes in the lymphoid follicles of the spleens and the lymph nodes (Figs. 1a, 1b,5). Large blastic cells within germinal centers also showed positive membrane fluorescence but weaker than that of the lymphocyte corona. ARBS-reactive cells were also observed in marginal zone (MZ) of the spleen. However, plasma cells in the medulla of the lymph nodes and in the MZ of

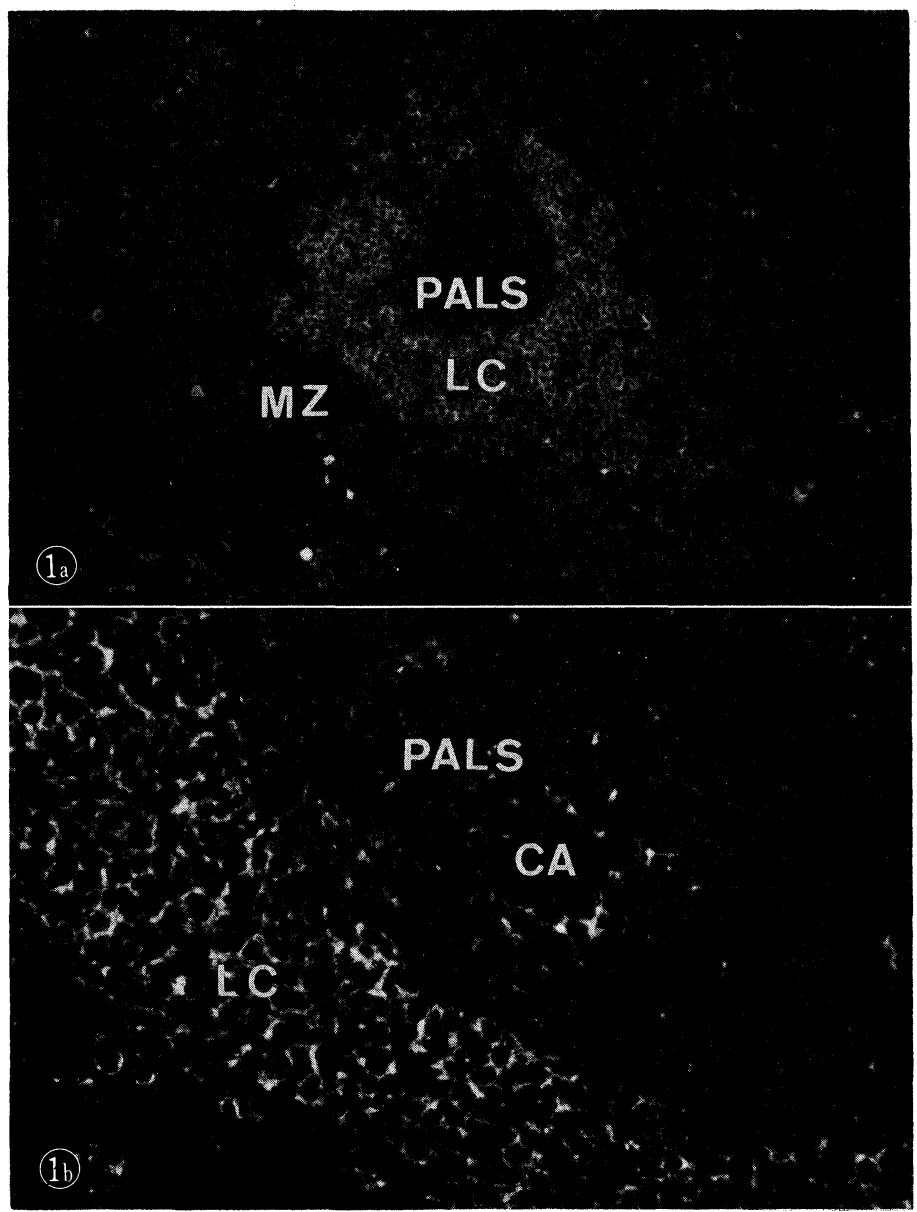

Fig. 1. Rat spleen exposed to ARBS. a: Lymphocytes in a periarteriolar lymphoid sheath (PALS) show no fluorescence, whereas those in a lymphocyte corona (LC) around PALS show bright fluorescence. $\times 32$. $b$ : Higher magnification of immunofluorescence with ARBS. $\times 160$. Lymphocytes in lymphocyte corona are strongly stained. CA, central arteriole; MZ, marginal zone. 
the white pulp showed weak membrane fluorescence but no cytoplasmic fluorescence with ARBS.

In contrast to ARBS, anti-rat T lymphocyte serum (ARTS)-reactive cells were located selectively in the thymus-dependent areas, i.e., paracortical areas in the lymph node and periarteriolar lymphoid sheath (PALS) in the spleen. Lymphoid follicles and germinal centers were not stained with ARTS. T cells reactive with ARTS were detected in $\mathrm{MZ}$ of the spleen as well as $\mathrm{B}$ cells reactive with ARBS (Figs. 4, 6).

Indirect immunofluorescence studies using various rabbit anti-rat heavy chains of Ig sera, i.e. anti- $\mu$ chain serum, anti- $\gamma$ chain serum, and anti- $\alpha$ chain serum (Miles Laboratories, Elkhart, Ind.), were also carried out on lymph nodes
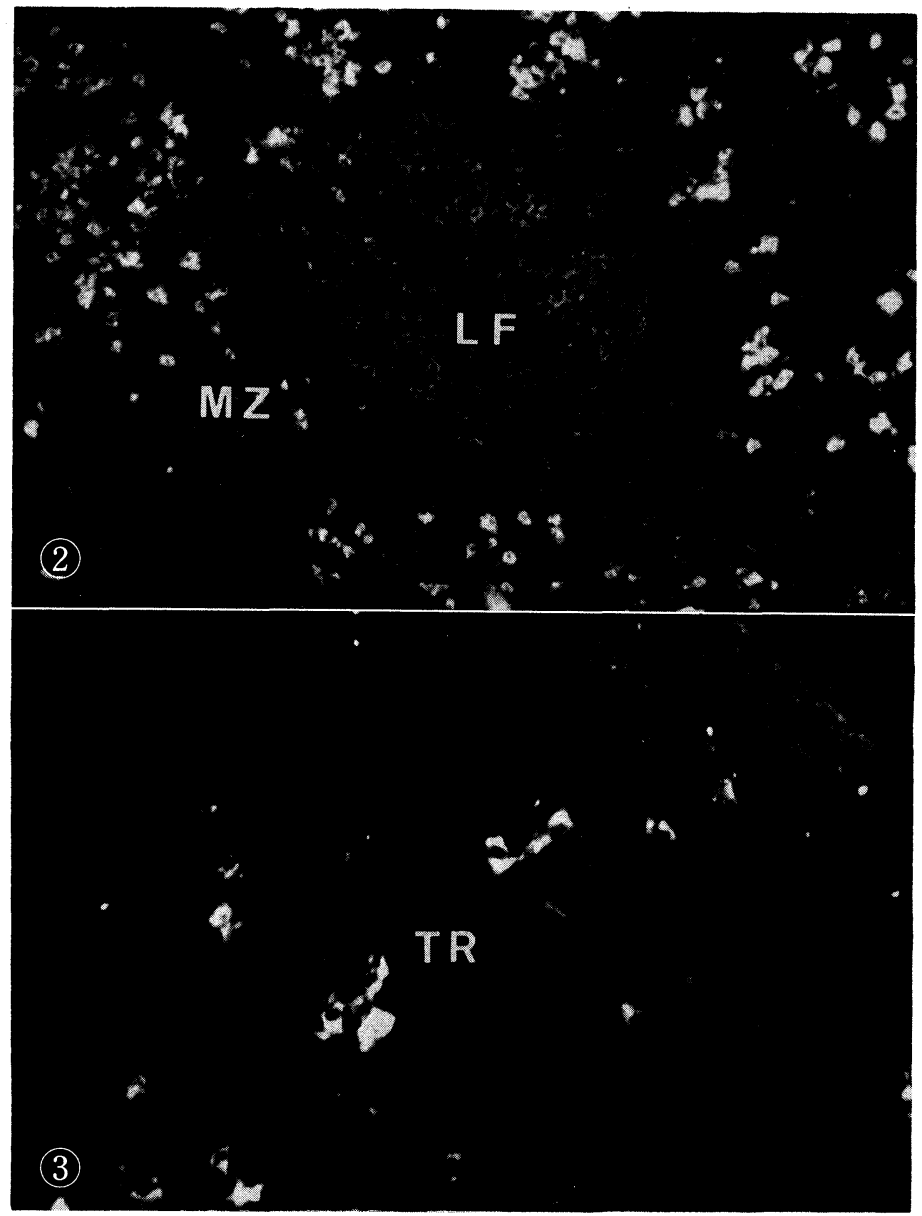

Fig. 2. Rat spleen exposed to anti-rat $\mu$ chain serum. Lymphocytes in a lymphoid follicle (LF) show bright membrane fluorescence and plasma cells in the marginal zone (MA) show positive cytoplasmic fluorescence. $\times 32$.

Fig. 3. Rat spleen exposed to anti- $\gamma$ chain serum. Cells with cytoplasmic fluorescence are located along the trabecula (TR) of red pulp. $\times 80$. 


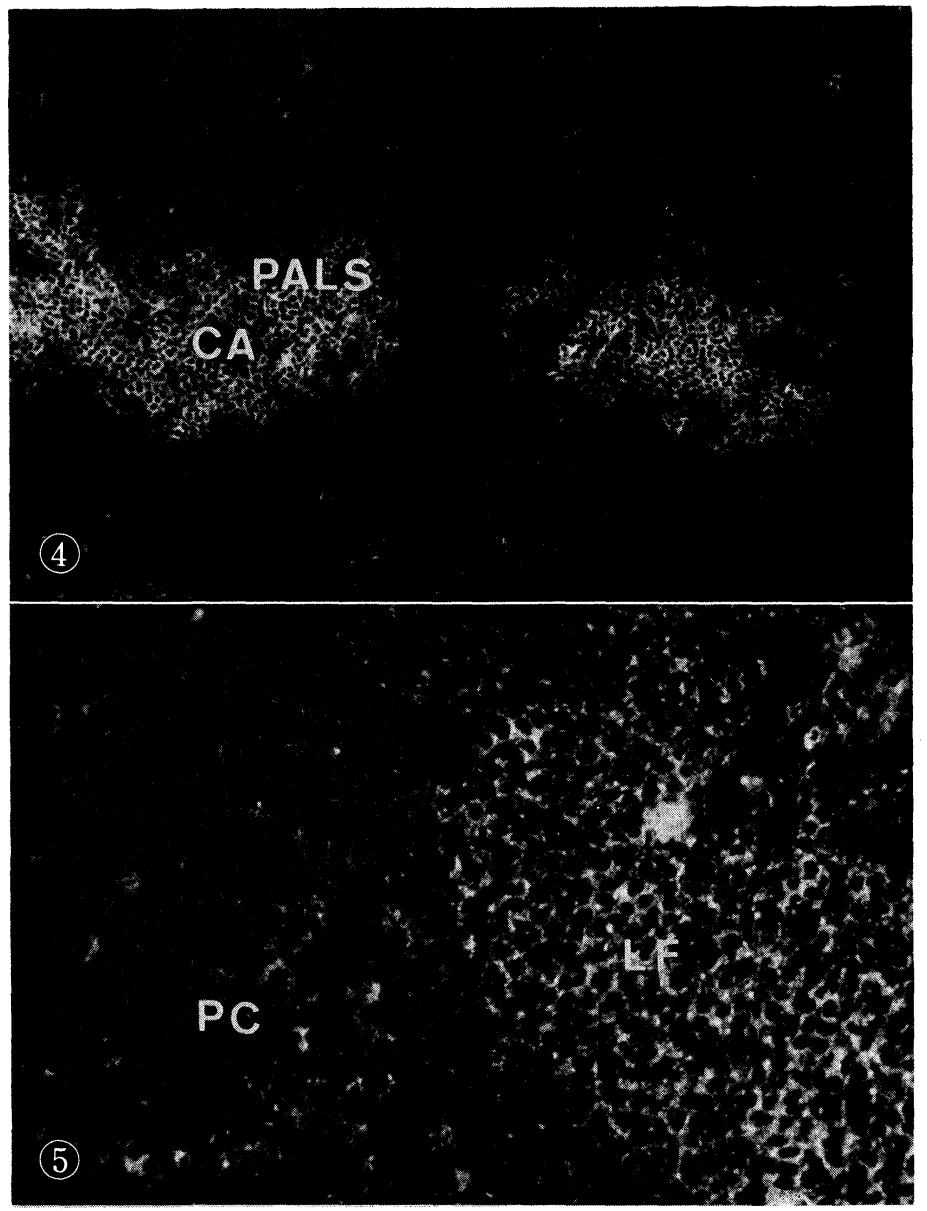

Fig. 4. Rat spleen exposed to ARTS. Lymphocytes in PALS are only strongly stained. $\mathrm{CA}$, central arteriole. $\times 32$.

Fig. 5. Rat lymph node exposed to ARBS. Lymphocytes in the lymphoid follicle show bright fluorescence. $\mathrm{PC}$, paracortex. $\times 80$.

and spleens of rats. The lymphocytes with membrane IgM were detected in lymphocyte corona, germinal center of lymph nodes and spleen, and MZ of white pulp. This distribution resembled that of ARBS-reactive cells. The lymphocytes with cytoplasmic IgM were observed mainly in medullary cords of the lymph node, and adjoining paracortical areas and $\mathrm{MZ}$ of the spleen (Figs. 2, 7). The lymphocytes with cytoplasmic IgG or IgA were observed mainly in medullary cords but only a few in lymphoid follicles of the lymph node and the spleen (Fig. 3).

Lymphocytes in the lymphoid follicle of mouse lymph node showed positive fluorescence with ARBS (Fig. 8).

\section{Discussion}

The B cell specificity of ARBS used was based on the following observations: 


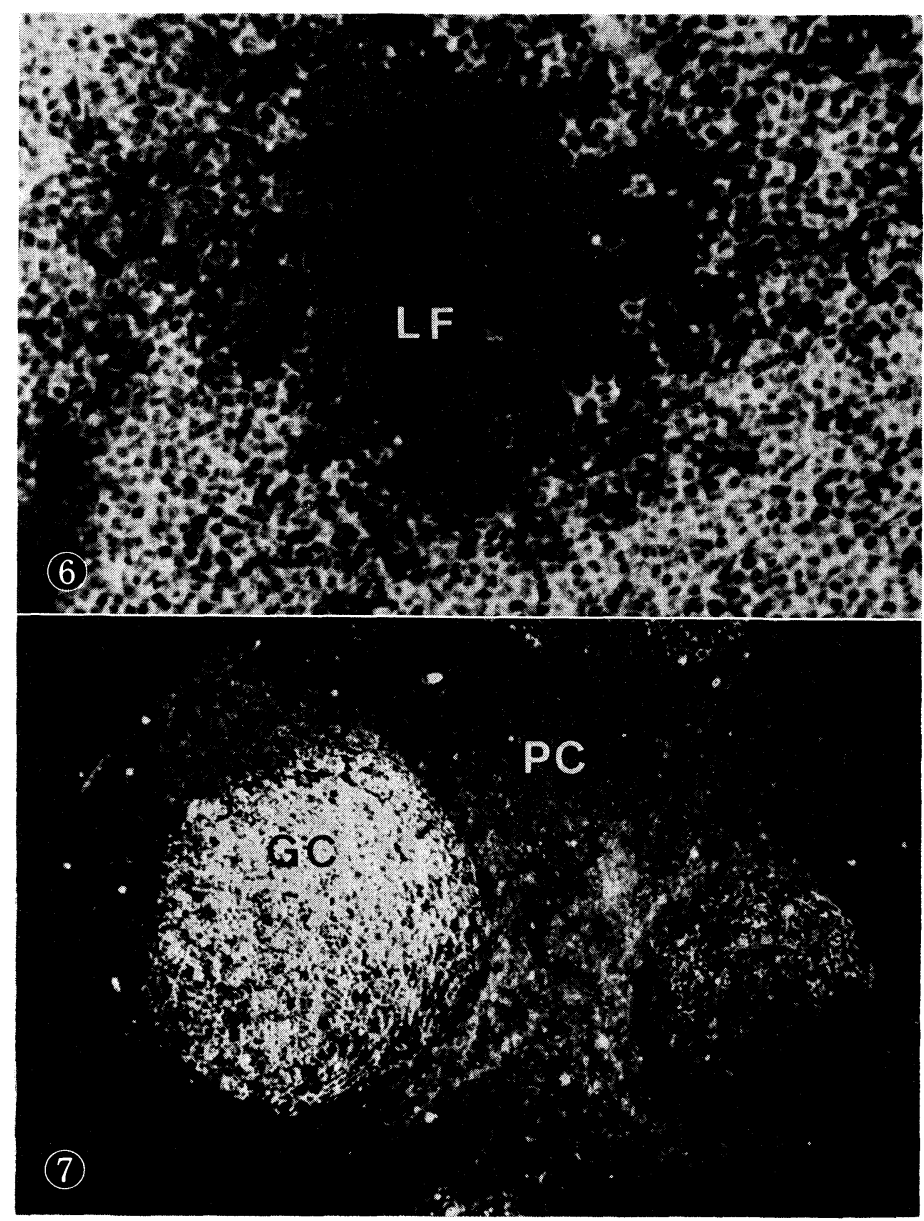

Fig. 6. Rat lymph node exposed to ARTS. Paracortical lymphocytes are brightly stained, whereas follicular lymphocytes and germinal center cells are not. LF, lymphoid follicle. $\times 80$.

Fig. 7. Rat lymph node exposed to anti-rat $\mu$ chain serum. Follicular lymphocytes and germinal center cells, especially the latter, show bright fluorescence. GC, germinal center; PC, paracortex. $\times 32$.

a) ARBS lysed a number of spleen and lymph node cells, and the percentage of lysed cells was correlated well to that of cells forming EAC rosettes and surface Ig positive cells in respective organs. b) ARBS could not inhibit the response of spleen cells to PHA which stimulates only $\mathrm{T}$ cells in vitro (Stobo et al. 1972). c) As determined by immunofluorescence, ARBS-reactive cells were localized selectively in lymphoid follicles, which was the same as the results with anti-human B cell serum described before (Kikuchi and Yamanaka 1978); whereas, ARTS stained selectively the thymus-dependent area of the lymph node and the spleen, i.e., paracortical areas and periarteriolar lymphoid sheaths. Anatomical localizations of $\mathrm{B}$ and $\mathrm{T}$ cells in the rat spleen and lymph node are schematized in Fig. 9. 


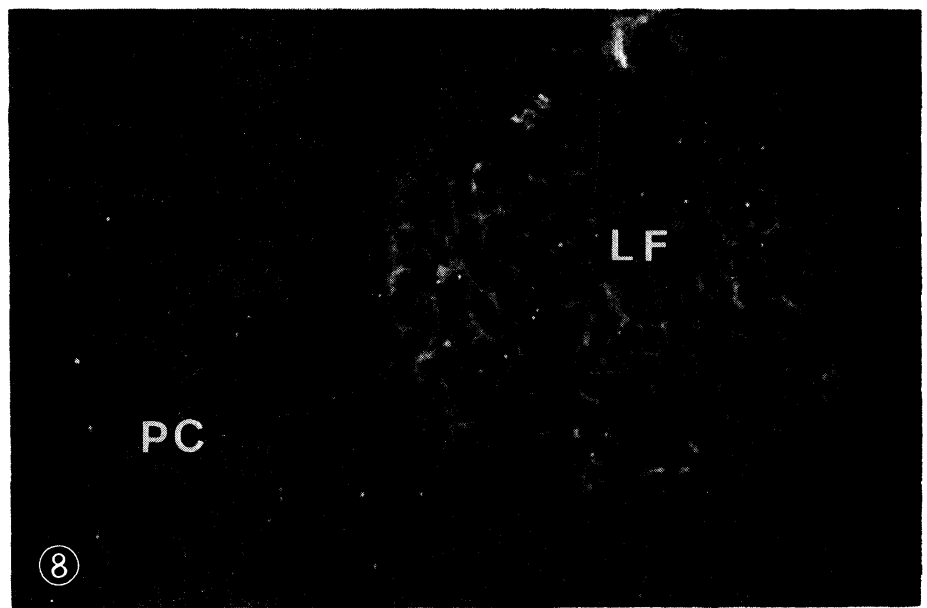

Fig. 8. Mouse lymph node exposed to ARBS. Lymphocytes in the lymphoid follicle (LF) are only stained. PC, paracortex. $\times 80$.
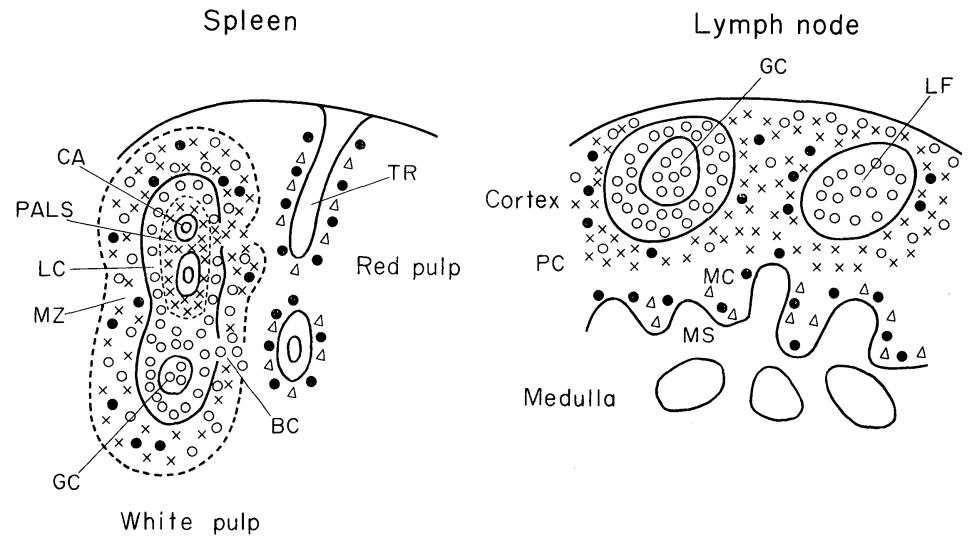

Fig. 9. Schematized diagram of rat spleen and lymph node showing anatomical localizations of lymphocytes with various surface markers.

$\times$, T lymphocyte (ARTS+); o, B lymphocyte (ARBS+, sIg+); •, plasma cell (cytoplasmic IgM+); $\Delta$, plasma cell (cytoplasmic $\operatorname{IgG}$ or $\operatorname{IgA}+$ ). BC, bridging canal; CA, central arteriole; GC, germinal center; LC, lymphocyte corona; LF, lymphoid follicle; MC, medullary cord; MS, medullary sinus; MZ, marginal zone; PALS, periarteriolar lymphoid sheath; PC, paracortex; TR, trabecula.

As assessed by quantitative absorption studies, no antigens (RBLA) demonstrated by ARBS did exist in the liver or the brain. Thymus cells, which were rich in $\mathrm{T}$ cells, had a weak capacity of absorbing anti-B cell activity of ARBS. On the other hand, no ARBS-reactive antigens were detected in $\mathrm{T}$ cells from lymph nodes purified by nylon wool column filtration. These facts suggest the presence of a small amount of ARBS-reactive antigen in some rat thymocytes. Interestingly, McMaster and Williams (1980) revealed the presence of Ia-glycoproteins in the rat 
thymus by using monoclonal antibodies; i.e., the monoclonal anti-Ia rat antibodies bound to the majority of peripheral B lymphocytes and $18 \%$ of thymocyts. These data indicate the similarity of ARBS to the anti-rat Ia antibodies.

Although lymph node cells showed a considerable absorption capacity, their RBLA content estimated was lower than that of spleen cells. As we described elsewhere (Ishii et al. 1975), ARBS also reduced the Con A response, whereas it did not affect their reactivity to PHA. Such a differential effect of antisera on lymphocyte reactivity to PHA and Con A, adding to the fact that ARBS had the cross-reactivity with mouse B cells, also indicated the similarity to anti-Ia antibodies. Niederhuber et al. (1976) demonstrated that both PHA and Con A responses were impaired with anti-Ia and $\mathrm{C}$.

The anatomical localization of rat B cells in lymphoid tissues coincides with the thymus-independent region as proposed in mice (Nossal and Pike 1973) and in human (Ishii et al. 1975). In frozen sections of rat spleens and lymph nodes, the majority of ARBS-reactive cells were found concentrated in lymphoid follicles. Goldschneider and McGregor (1973) have observed almost similar distribution of $\mathrm{B}$ cells in the rat lymphoid tissue. However, unlike ALSB of Goldschneider, ARBS, after appropriate absorption, did not react with rat gamma globulin. Either, plasma cells showed no cytoplasmic fluorescence with ARBS.

In this paper, we emphasize the usefulness of ARBS in the detection of $\mathrm{B}$ cells, especially of the anatomical distribution of B cells by using immunofluorescence techniques. Various monoclonal anti-rat lymphocyte sera have been available recently. Heterologous anti-rat lymphocyte sera, i.e., ARBS and ARTS, may be as useful as these sera in identifying $B$ cells or $T$ cells in tissue sections.

\section{References}

1) Goldschneider, I. \& McGregor, D.D. (1973) Anatomical distribution of T and B lymphocytes in the rat. J. exp. Med., 138, 1443-1465.

2) Ishii, Y., Koshiba, H., Ueno, H., Maeyama, J., Takami, T., Ishibashi, F. \& Kikuchi, K. (1975) Characterization of human B lymphocyte specific antigens. J. Immunol., 114, 466-469.

3) Ishii, I., Koshiba, H., Yamaoka, H. \& Kikuchi, K. (1976) Rat T lymphocytespecific antigens and their cross-reactivity with mouse $\mathrm{T}$ cells. J. Immunol., 117, 497-503.

4) Kikuchi, K. \& Yamanaka, N. (1978) Malignant lymphoproliferative disorders. J. clin. Sci., 14, 442-452.

5) McMaster, W.R. \& Williams, A.F. (1980) Identification of Ia glycoproteins in rat thymus and purification from rat spleen. Europ. J. Immunol., 9, 426-433.

6) Niederhuber, J.E., Frelinger, J.A., Dine, M.S., Shoffner, P., Dugan, E. \& Shreffler, D.C. (1976) Effects of anti-Ia sera on mitogenic responses. II. Differential expression of the Ia marker on phytohemagglutinin and concanavalin A-reactive T cells. J. exp. Med., 143, 372-381.

7) Nossal, G.J.V. \& Pike, B.L. (1973) Studies on the differentiation of B lymphocytes in the mouse. Immunology, 25, 33-45.

8) Stobo, J.D., Rosenthal, A.S. \& Paul, W.E. (1972) Functional heterogeneity of murine lymphoid cells. I. Concanavalin A and phytohemagglutinin. J. Immunol., 108, 1-17. 